\title{
Locomotor training: Experiencing the changing body
}

\author{
Elizabeth M. Hannold, PhD; ${ }^{1-2 *}$ Mary Ellen Young, PhD, CRC; ${ }^{2}$ Maude R. Rittman, PhD, RN; ${ }^{1,3}$ \\ Mark G. Bowden, MS, PT; ${ }^{4}$ Andrea L. Behrman, PhD, PT ${ }^{4-5}$ \\ ${ }^{1}$ Department of Veterans Affairs (VA) Rehabilitation Outcomes Research Center, Gainesville, FL; ${ }^{2}$ Department \\ of Rehabilitation Counseling and ${ }^{3}$ College of Nursing, University of Florida, Gainesville, FL; ${ }^{4}$ VA Brain Rehabilitation \\ Research Center, Malcom Randall VA Medical Center, Gainesville, Florida; ${ }^{5}$ Department of Physical Therapy, University \\ of Florida, Gainesville, FL
}

\begin{abstract}
This study examined the experiences of persons with incomplete spinal cord injury who participated in locomotor training (LT). LT is an emerging rehabilitation intervention for enhancing the recovery of walking in persons with central nervous system disorders. Multiple interviews and field observations provided data from eight participants, including four veterans. Findings indicate that experiences of bodily changes were prevalent among participants. Themes included (1) experiencing impaired or absent proprioception, (2) struggling for bodily control, and (3) experiencing emergent bodily sensations. Themes 1 and 2 reflected bodily disruption as a result of spinal cord injury and were challenging to participants as they attempted to reconnect the body and self through LT. Theme 3 reflected bodily sensations (burning, soreness) that were seen as positive signs of recovery and resulted in hope and motivation. Understanding how LT participants experience bodily changes may enable therapists to develop improved participant-centered intervention approaches.
\end{abstract}

Key words: body modification, locomotor training, patient experiences, physical therapy techniques, qualitative research, recovery of function, rehabilitation, spinal cord injury, treadmill, walking.

\section{INTRODUCTION}

The patient perspective is recognized as a vital component of the rehabilitation process [1]. The professional literature has increasingly supported looking to the patient for insight on an array of rehabilitation-related issues, including priorities for rehabilitation research, interventions, and innovations [1-4]; evaluation of rehabilitation practice and process [5-12]; evaluation of specific interventions and devices [13-15]; and development of patient-centered outcome measures [16-18]. Textbooks have also emphasized the importance of incorporating patients' priorities and preferences throughout the rehabilitation process-from goal setting and treatment planning to evaluating associated outcomes [19-20]. The same literature indicates, however, that few studies have examined the personal impact of locomotor training (LT)

\footnotetext{
Abbreviations: BRCC $=$ Brain Rehabilitation Research Center of Excellence, BWS = body-weight support, FES = functional electrical stimulation, FNS = functional neuromuscular stimulation, I-SCI = incomplete spinal cord injury, LT = locomotor training, NCMRR = National Center for Medical Rehabilitation Research, NICHD = National Institute of Child Health and Human Development, RORC = Rehabilitation Outcomes Research Center, SCI = spinal cord injury, VA = Department of Veterans Affairs.

*Address all correspondence to Elizabeth M. Hannold, PhD; VA Rehabilitation Outcomes Research Center, North Florida/South Georgia Veterans Health System, 1601 SW Archer Road, Mail Stop 151B, Gainesville, FL 32608; 352376-1611, ext 4947; fax: 352-271-4540. Email:

Lisa.Hannold@med.va.gov
}

DOI: 10.1682/JRRD.2005.07.0122 
models, which are emerging therapeutic interventions for improving gait and mobility in persons with central nervous system-related disabilities, including incomplete spinal cord injury (I-SCI) and stroke.

For the purposes of this work, LT is defined as a therapeutic program aimed at the recovery of walking through intense practice of the task of walking. LT incorporates use of a body-weight support (BWS) system, a treadmill, and manual assistance. The BWS and treadmill provide a controlled environment that promotes normal walking mechanisms. The principles of training applied in the BWS and treadmill environment also extend to training over ground. Alternative methods for promoting relearning of walking include robotic-assisted LT, which uses a gait-driven orthosis to facilitate stepping [21-22], and functional electrical stimulation (FES)- or functional neuromuscular stimulation (FNS)-assisted LT, which use FES/FNS technology as facilitators [23-28]. Unless otherwise specified, we use the term "LT" to denote manually assisted LT and the transfer of skills to walking over ground. The objective of LT is independent community walking at normal speeds without assistive devices or braces [29].

LT studies have shown that the human lumbosacral spinal cord remains capable of responding to sensory information related to locomotion even when damaged [30-32]. Edgerton et al. attribute this phenomenon to circuits within the spinal cord that act as central pattern generators [30]. These circuits exhibit neural plasticity and are capable of motor learning if properly activated. Edgerton et al. maintain that for activation to occur, specific sensory input associated with performance of a motor task must be provided and followed by repetitive practice of the task [30]. These requirements are fulfilled during LT.

Over the past 15 years, LT has been investigated in various reports, ranging from case studies [29,33-35] to randomized clinical trials [36]. These studies, however, have focused on gait-specific outcomes (gait speed, walking independence) or have described improved stepping patterns and mechanics during treadmill walking [33-44]. The perspectives of LT participants is an important aspect of the intervention that requires further study.

To date, Nymark et al. offer the most thorough examination of participant perspectives on LT [41]. As part of a 12-week LT pilot study, they used a questionnaire and focused interviews to garner personal feedback from five participants with I-SCI. Nymark et al. reported that participants found LT physically and emotionally challenging and beneficial. Participants also identified increased hope and confidence as a result of LT. A closer examination of
Nymark et al.'s questionnaire items and interview questions, however, suggests that further investigation is warranted. For example, items and questions were largely directed at participant satisfaction with the protocol used in the LT pilot study, for example, how LT was implemented. Conversely, attention to participants' experiences and perceived outcomes of LT was limited. Furthermore, many questions in the 16-item questionnaire were either closeended or required ranked responses. Such format choices restrict the opportunity for nonstructured dialogue and discussion and indicate that the feedback provided by the participants in the Nymark study was only minimally tapped.

More recent LT studies have pilot tested quantitative measures that assess changes in participants' subjective well-being and quality of life as a result of LT [42-44]. While one study of 14 LT participants reported statistically significant increases in life satisfaction [44], smaller studies $(n=3)$ reported no change in life satisfaction [43] and small but inconsistent increases in quality of life [42]. Such variable findings suggest the need for additional studies on participant perceptions of LT.

Specifically, a more comprehensive understanding of the value and meaning of LT for participants is needed for defining indicators of participant satisfaction with the intervention, including how it affects their quality of life and motivation for recovery. Gaining an understanding of the participants' LT experience also provides therapists with information that may ensure that interventions are sensitive to the LT participants' needs and concerns. Information obtained from participants' perspectives on LT may also be used in the development of improved LT outcome measures. To begin to bridge this gap in knowledge, we aimed to answer two research questions: (1) How do persons with I-SCI describe their LT experiences? and (2) What changes do persons with I-SCI report as a result of LT?

\section{METHODS}

We used qualitative methods to answer the research questions. Specifically, this study used grounded theory to guide data collection, analyses, and theory development [45]. Grounded theory is a qualitative research approach in which hypotheses and theory are not preconceived but rather generated directly from qualitative data [45]. Grounded theory methods are particularly appropriate for research investigating phenomena about which little is known, especially phenomena that involve personal experiences and processes [45-46]. The use of qualitative 
methods for investigating pertinent experiences associated with spinal cord injury (SCI) is well-established [7,47-50]. Qualitative research methods were also recently supported as an approach to obtaining consumer perspectives that may help identify priorities for rehabilitation-related SCI research [1].

The study was approved by the Department of Veterans Affairs (VA) Subcommittee for Clinical Investigations and the local institutional review board prior to participant enrollment. Every participant completed the informed consent process and signed a consent form. All participants enrolled completed the study.

\section{Sample}

The sample consisted of eight persons with I-SCI. All members of the sample were currently or formerly enrolled in an ongoing LT intervention study and were recruited by the principal investigator. Seven males and one female participated. Four participants were veterans. We use pseudonyms in this article to protect the participants' identities. The Table summarizes the demographics of the sample.

Two of the participants were newly enrolled in the LT intervention study and were recruited for this study before beginning the intervention. These participants were followed throughout the intervention and provided prospective data. The other six participants were former LT study participants and provided retrospective data. All participants completed 45 LT sessions; each session included 30 minutes of training followed by over ground walking practice. LT sessions took place five times a week for 9 weeks.

\section{Justification of Sample Size}

In qualitative studies, the investigator's goal is to use a sample size that will lead to theoretical saturation. Theoretical saturation is achieved when themes become recurrent in the data and no new themes are identified [45,51]. In this study, the participant sample yielded 60 observations of LT sessions and 14 participant interviews. Ongoing data analyses and peer debriefing sessions confirmed that saturation of data was, in fact, achieved.

\section{Inclusion and Exclusion Criteria}

Inclusion and exclusion criteria reflect those of the LT study. Inclusion criteria for participants included (1) age of 18 years or older, (2) diagnosis of first-time SCI, including etiology from trauma, vascular, or orthopedic pathology at cervical or thoracic levels, (3) post-SCI time frame of 3 months to 3 years, (4) SCI diagnosis defined by the American Spinal Injury Association Impairment Scale as category C or D, (5) medically stable condition, (6) documented medical approval from the participant's personal physician, (7) ability to walk independently a minimum of 12.19 consecutive meters (40 feet) with or without an assistive device (and/or contact guard), (8) minimum of $30 \mathrm{~min}$ utes (total) each day spent standing or walking, (9) if on antispasticity medication, maintenance of routine dosage throughout LT, or if not on antispasticity medication, not initiating its use throughout LT, and (10) ability to give informed consent. Exclusion criteria for participants included (1) current participation in a rehabilitation program or another research protocol that could interfere with or influence LT outcome measures and (2) history of congenital SCI or other degenerative spinal disorders.

Table.

Demographic characteristics of participants.

\begin{tabular}{|c|c|c|c|c|c|c|c|}
\hline Participant ${ }^{*}$ & Sex & Race/Ethnicity & Age & Injury Level & Injury Date & $\begin{array}{c}\text { Locomotor } \\
\text { Training Date }\end{array}$ & Veteran Status \\
\hline Abe & Male & White & 49 & C5, C6 & 1999 & 2001 & Veteran \\
\hline Chuck & Male & White & 44 & C6 & 1998 & 2001 & Veteran \\
\hline Dan & Male & African American & 60 & C5 & 1999 & 2002 & Veteran \\
\hline Ken & Male & White & 56 & C5, C6 & 2002 & 2003 & Veteran \\
\hline Lynn & Female & White & 46 & C5, C6 & 2002 & 2003 & Nonveteran \\
\hline
\end{tabular}




\section{Locomotor Training Procedures}

Daily LT sessions included step training on the treadmill with partial BWS and manual assistance from trainers followed by over ground training. Manual assistance promoted participant achievement of the trunk posture, pelvic movements, and limb kinematics consistent with the task of walking. BWS was initially set at 40 percent and treadmill speed approximated normal walking speed, as feasible, while maintaining overall kinematics consistent with the task of walking. Over ground training consisted of an immediate assessment of the participant's ability to stand and/or walk independently over ground and an evaluation of deficits that limited achievement of this goal. These deficits became the goals for the next day's training session. Additionally, over ground training addressed translation of the skills from the treadmill to the home and community by identifying practical ways for the participant to incorporate new skills into his or her everyday activities [29,35]. Training goals were set for endurance (duration of stepping bouts and/or total stepping time, BWS, speed, independence, postural control, kinematics), adaptability to the environment, and behavioral goals of the individual.

\section{Data Collection}

Data were collected via in-depth semistructured interviews and observations of participants. We used interviews to obtain data on the participants' thoughts and feelings related to all aspects of their LT experiences. Interview guides consisting of open-ended questions were used for all interviews. Observations of LT sessions were also conducted and field notes were recorded. Field notes documented the participant's observed affect, training activities, interactions with LT staff, and interactions with family and significant others. Comments, responses, and significant dialogue were recorded in the field notes. Observations were conducted live and via videotaped LT sessions.

\section{Data Analyses}

Audiotaped interviews were transcribed verbatim as Microsoft Word $^{\circledR}$ documents (Microsoft Corporation, Redmond, Washington) and verified. Handwritten field notes were typed into Microsoft Word ${ }^{\circledR}$ documents and verified against videotapes of corresponding LT sessions. All Microsoft Word ${ }^{\circledR}$ documents were converted to text files and then imported into the N6 ${ }^{\circledR}$ qualitative software program (QSR International Pty, Ltd; Melbourne, Aus- tralia) for coding. $\mathrm{N}^{\circledR}{ }^{\circledR}$ facilitates the systematic analysis of qualitative data by enabling users to develop a coding framework. Once imported, N6 ${ }^{\circledR}$ removes formatting from text documents and assigns consecutive numbers to every line of text. This process facilitates coding and record keeping. Users are able to select/highlight a specific segment of text and then assign a code to the text segment. The coding process involves the review of each line of text for prominent themes. This careful line-byline review of data enables researchers to identify themes from small and large segments of text-from single words and phrases to large text blocks. To facilitate data analyses, $\mathrm{N} 6{ }^{\circledR}$ users may retrieve coded data according to line numbers of the coded text.

Data were analyzed systematically by use of the constant, comparative method that is common in qualitative analysis [45]. All documents were subjected to the coding framework. If an existing code was representative of the data, the data segment was coded accordingly. If existing codes were not representative of the data, a new code was added to the framework and the data were coded. Once all data were coded, all text related to individual codes was retrieved and recurrent themes and patterns were defined.

Guidelines for ensuring the trustworthiness or quality of conclusions drawn from qualitative data were followed throughout the study [52]. Detailed documentation of coding decisions and personal reflections about data were maintained as an "audit trail," which is one approach for ensuring that conclusions remain objective and confirmable by others [52]. To prevent researcher bias and confirm the credibility and reliability of conclusions, we conducted regular peer debriefing sessions with another qualitative researcher. The peer inspected the data, codes, and evolving analyses and interpretations to verify the soundness of decisions. Triangulation, the use of multiple data-collection methods [46,51], was used for enhanced credibility of study conclusions. Data were collected through two methods: in-depth interviews and participant observations of LT sessions.

\section{RESULTS}

Numerous themes and patterns representative of the multifaceted nature of participants' LT experiences were identified from the data. Participants' descriptions of their experiences reflected interdependent relationships 
among the physical, cognitive, and emotional domains and were reciprocally related to the LT therapeutic process and outcomes (Figure). Experiences of bodily changes were a dominant pattern and are the focus of this article. Three themes associated with the changing body during LT are described: (1) experiencing impaired or absent proprioception, (2) struggling for bodily control, and (3) experiencing emerging bodily sensations.

\section{Experiencing Impaired or Absent Proprioception}

Secondary to I-SCI, some LT participants were left with an impaired or absent sense of proprioception. For these participants, the requirements of LT made them more aware of the extent of their proprioceptive impairments. The impact that impaired or absent proprioception had on these participants during the LT process was clear from the data. For example, these participants frequently reported difficulty perceiving their foot placement and body movements during LT and identified these factors as affecting their ability to achieve good quality steps and/or posture while stepping on the treadmill and walking over ground. When discussing the challenges of LT, for instance, Dan described how his impaired sense of

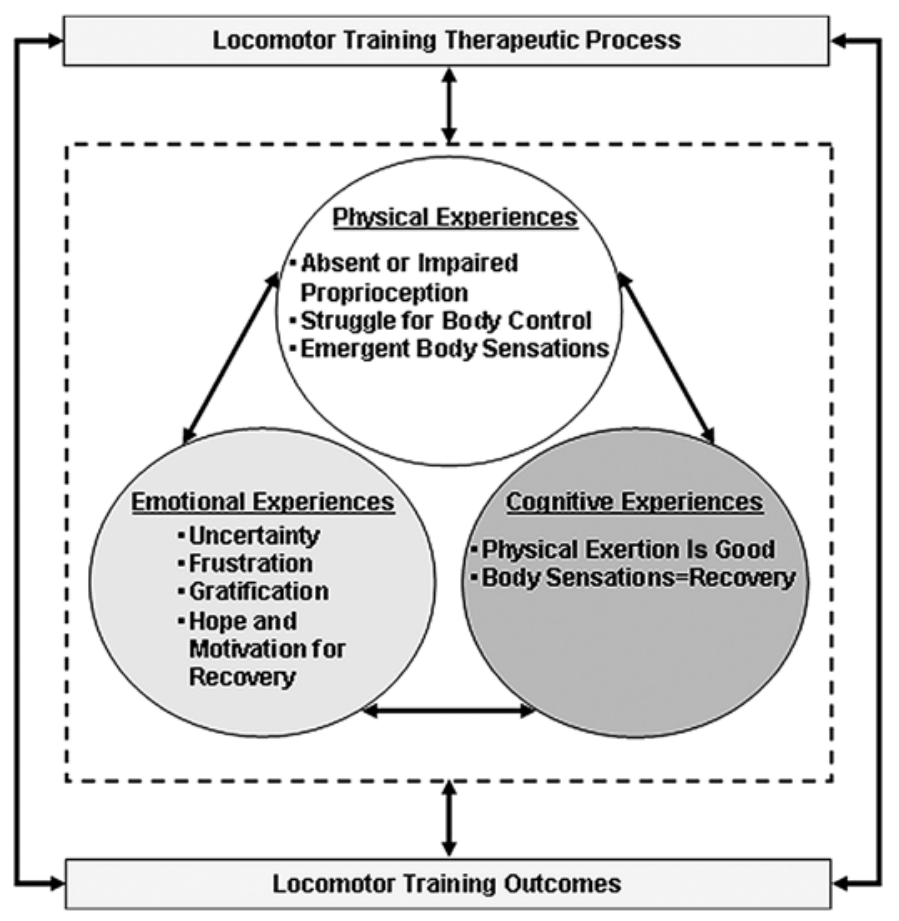

Figure.

Participants' experience of changing body during locomotor training. proprioception affected the training. He stated, "It's, believe it or not, it gets hard. You see by only havin' about from my waist down I only have maybe 50 percent of my feeling back. So when you place your foot out in front of the other one, you really don't even know where it's at." For Dan and some other LT participants, an impaired or absent sense of proprioception rendered LT challenging and, at times, difficult and frustrating.

While an impaired or absent sense of proprioception may lead to frustration for those LT participants who experience it, the social sciences literature provides a less medical, more holistic interpretation of such experiences. Becker, for example, uses the term "disruption” to characterize the impact of a chronic illness or disability on individuals [53]. According to Becker, a person's reliance on the "orderly functioning" of his or her body drives the person's understanding of self and the world. Becker asserts that when the body is free from disease or disability and is working properly, individuals are unaware of bodily functions and take their bodies for granted [53]. When the body is suddenly disrupted by I-SCI, however, individuals become aware of their bodies and functions and begin to question their sense of self and place in the world. In the previous example, Dan described bodily disruption following I-SCI. For Dan, the previously automatic process of walking had become a difficult task. Dan related how his sensation and proprioceptive sense had been disrupted by his injury and altered his identity as an independent walker.

The theme of bodily disruption was further evident during observation of LT sessions. During one training session, for example, the therapist asked Ken if he understood what he (the therapist) meant when he said "relax your left leg, keep your heel on the ground longer.” Ken indicated that he understood the command but could not feel if he had made the change. Similarly, in videotaped training sessions, Abe was frequently observed asking for feedback about the position of his body while stepping on the treadmill. For example, during one session, Abe, who had difficulty holding his trunk upright, asked, "I feel like I'm leanin' forward, am I?” In Abe's case, the uncertainty he experienced because of an impaired sense of proprioception led to a discrepancy in how he perceived his performance on the treadmill versus how the therapists viewed his performance. Abe frequently made negative comments and appeared frustrated with his performance, while therapists reassured him that it "wasn't that bad." When asked about this apparent discrepancy during his 
interview, Abe commented, "Well, I think the feedback I'm gettin' up in my head from down below is not, I'm not really perceivin' the way it really is."

Dan, Ken, and Abe's examples indicate the challenges that impaired or absent proprioception presented to some participants during LT. These participants' inability to perceive their own body position and movement often led to uncertainty and frustration when they attempted to implement changes as directed by therapists. An impaired or absent sense of proprioception also made some participants' self-assessment of their progress more difficult when stepping on the treadmill or during overground training. From a social perspective, these examples indicate how bodily disruption due to I-SCI forces some LT participants to find new ways of gauging what their bodies are doing.

\section{Struggling for Bodily Control}

During interviews, all participants described how their loss of bodily control and function affected their lives postinjury. This theme of bodily control emerged again during descriptions of their LT experiences. These descriptions were often characterized by "bodily control talk" that illustrated the participants' struggle to regain control of their bodies. Bodily control talk included participants' references to their I-SCI-related functional limitations, symptoms, and consequences and how these factors affected LT.

For some participants, their loss of bodily control and function apparently was, at least initially, magnified as they tried to meet the functional demands of LT. As in the case of absent or impaired proprioception, LT caused some participants to be more aware of their limited ability to control their bodies. In the following example, Frank discusses his frustration with trying to gain control of his left leg during LT. He explains, "One of the areas that I felt most frustrated in, that uh, the left leg really lagged behind, the right, in terms of like being able to incorporate what it was suppose to do. And it was very hard to release that spasm and to shift weight. And so I think that the left leg was a source of frustration for me and I got agitated sometimes, with some of the staff." For Frank, trying to regain control of his left leg was especially difficult and frustrating because of involuntary muscle spasms. Possibly as a result of these involuntary movements, Frank spoke of his leg as if it had a will of its own-referring to its ability "to incorporate what it is suppose to do.” In a study of stroke survivors, Ellis-Hill et al. reported similar findings and characterized the experience as a separation of the body from the self [54]. According to Ellis-Hill et al., under typical circumstances, the self is understood to be inseparable from the body. The perceived loss of control following an illness or injury, however, results in a "self-body split" in which the body becomes objectified. In the previous example, Frank's allusion to his left leg as an entity separate and independent from himself is a clear example of how the body becomes objectified during rehabilitation, in this case, through the process of LT.

Data further indicated how the struggle for bodily control was extended to the LT therapeutic process. For participants like Frank, who experienced spasms or increased muscle tone because of his I-SCI, the action of stepping on the treadmill often triggered increases in the number and/or intensity of spasms. Consequently, therapists would attempt to decrease spasms or tone by altering their leg-training technique, adjusting the BWS setting, or varying the treadmill speed to find an optimum speed at which spasms would be minimized. In these cases, regaining control of a participant's leg became a shared effort between the LT participant and the therapist. From a social perspective, therapists served as the bridge to recovery-helping participants reconnect the body and self through the LT therapeutic process, and ultimately, improving gait and mobility.

The theme of self-body split recurred in other participants' descriptions of their struggle to gain bodily control during LT. Similar to Frank, Abe had involuntary movements and muscle spasms and, consequently, depicted a struggle for control between him and his body. Through the use of metaphors, for example, Abe described the intensity with which he experienced involuntary muscle spasms: "It was like a, it was, it's just a sudden thing, like a, 'Pow!' You know like a firecracker it would just, launch your foot.” Again, Abe's experience poignantly illustrates a separation of the body and self. Abe's body seemed to act on its own and his awareness of this fact struck him: "Pow!" Abe's sense that his foot was being launched by some outside force emphasized the magnitude with which participants often perceived a lack of bodily control during LT.

Observations of Abe's training sessions provided further evidence of his frustration with his inability to control his body. During one session, Abe repeatedly experienced muscle spasms in his leg when stepping on the treadmill and asked, “Just a second, what's goin' on 
here? What's goin' on?” Sounding frustrated and bewildered, Abe appeared to plead to the therapists for help in understanding his poor bodily control. Frank and Abe's examples indicate how the process of trying to regain control of the body through LT may result in frustration but, at a deeper level, this struggle for control actually represents the struggle to reconnect the body with the self following I-SCI.

\section{Experiencing Emerging Bodily Sensations}

In addition to the experiences of an impaired or absent sense of proprioception and the struggle to regain bodily control, some participants described various bodily sensations that emerged during LT. While only Ed identified the burning sensations as pain, other participants labeled the sensations as discomfort, soreness, tingling, or burning. Interestingly, data indicate that although these experiences were cast as negative experiences, the participants typically described them as positive signs of recovery. Apparently, the paralysis and/or sensory limitations secondary to I-SCI caused participants to construe any new sensations resulting from LT as a reawakening of their bodies. All sensations were perceived as "good" sensations-even those that under typical circumstances might be viewed as negative. Data indicate that the bodily sensations associated with LT resulted in feelings of hope among participants that, in turn, motivated them for further recovery.

When asked about bodily sensations during his interview, Frank responded, "There were a couple of times that I felt like there was an electrical current in some nerves but particularly in the front of my shin and up into my knee. It would be progressive, almost if you flicked the switch on some lights or one of those little radios. You can see it going and you can feel it move up, and it would move in rhythms. And that was fascinating to me. But that eventually stopped. The only time I ever experienced discomfort there, would be the muscles would cramp, like a charley horse. And that can be very discomforting-it's still not exactly pain, but it is painful.” Frank described two types of sensations. First, he characterized the tingling sensations he experienced as "electrical" in nature and was noticeably intrigued by the sensation. Frank's comparison of the sensation to electricity provides an insightful, appropriate metaphor for the neural recovery process. Although the electrical sensations were temporary, Frank construed them positively because, in his mind, they represented recovery-his nervous system had been reactivated as if by a "flick of the switch.” Second, although Frank described feeling discomfort from muscle cramps that resulted from LT, he did not depict the cramps as particularly negative experiences. Possibly, like the electrical sensations he experienced, Frank also perceived his muscle cramps as physiological indicators of recovery.

While Frank described feeling electrical sensations and discomfort because of muscle cramps, Chuck and Ken described feeling burning and soreness. In the following excerpt from Chuck's interview, he associates his thighs burning during LT as an indicator of a successful "workout." He stated, "Well I know when, I know when my muscles were fatigued, and, I used to lift weights a lot. And uh, and I know, you get a good muscle burn when you work out real hard. So I can tell when my thighs were burning that they got a good workout." Similar to Chuck, Ken associated the soreness he experienced from LT with intense physical exercise. For example, upon arriving for training one afternoon, a therapist asked Ken how he felt after walking on the treadmill for a longer period of time the previous day. The following dialogue ensued:

Ken: Sore this mornin'. Really. Well like I, ya know that kind of sore ya get when you haven't worked out in a long time? That kind of sore.

Therapist: It's a good kind of sore then?

Ken: Oh yeah! It was one I had to put every effort into gettin' outta bed this mornin'.

For Chuck and Ken, the burning and soreness they experienced from LT were reminiscent of feelings that they had experienced during strenuous exercise prior to the I-SCI. For them and other participants, the ability to once again engage in physical activity at a level of intensity strong enough to cause some discomfort appeared to be both a physically and emotionally gratifying experience. Just as the discomfort associated with strenuous exercise was interpreted as a sign that the exercise was effective, participants perceived the bodily sensations they experienced during LT as signs that their bodies were recovering and that LT was working to increase their mobility, endurance, and strength.

\section{DISCUSSION}

The rehabilitation field has historically regarded the body from physiological and functional perspectives, that 
is, as an object to be healed or restored. Conversely, the social sciences have interpreted the body within a broader social context, as a conduit for fulfilling social roles and establishing a sense of self $[48,55]$. Seymour, for example, provides a sociological interpretation of the body that is particularly relevant to the present study [48]. She explored and characterized the processes by which persons with SCI "remake" their injured bodies. Acknowledging that the body and the self are inseparable, Seymour uses the phrase "remaking the body" synonymously with "reconstruction of the self." Seymour recognizes that formal rehabilitation is an intrinsic part of remaking the body. However, she cautions that a medical approach aimed at restoring the body to "normal" function causes the resulting bodily changes to be evaluated by the standards of the rehabilitation industry [48]. Seymour's assertion is exemplified by the fact that efficacy studies of rehabilitation interventions primarily assess outcomes from the standpoint of the targeted functional changes, i.e., the bodily changes that are the "expected" outcomes of rehabilitation. Our study demonstrates, instead, that adding the perspectives of rehabilitation participants can more comprehensively delineate the personal impact and outcomes of rehabilitation interventions.

Our findings support and expand upon those of Nymark et al. [41], who similarly reported that LT participants found that the intervention was physically and emotionally challenging and increased their hope for recovery. Our findings extend this initial work by further describing why participants perceived LT as physically challenging and how LT increased their hope for recovery. Specifically, we found that participant experiences associated with an impaired or absent sense of proprioception and the struggle for bodily control caused LT to be perceived as physically demanding and that emerging bodily sensations during LT resulted in hope and motivation among participants.

The primary limitation of our study is that the results were derived from a convenience sample of eight participants with I-SCI from one LT study site. Although we obtained an in-depth understanding of these participants' experiences and perceptions, the participants were primarily white males and therefore not representative of the general population of persons with I-SCI. Similar studies with more diverse samples at other LT sites are needed for comparison of data across training environments, sex, race/ethnicity, and age.
Despite this limitation, our study findings indicate that each participant's experience of the changing body was a personally significant part of remaking the body through LT. These experiences held relevance for participants, and likewise, hold implications for therapists. Therapist education about the bodily changes that participants may experience during LT may lead to improved intervention approaches that are more participant- or patient-centered. For example, therapists may engage LT participants in an ongoing dialogue about their experiences with the intervention (i.e., impact on daily activities, health, body experiences). Using this information, therapists could better monitor the participants' status and determine whether and/or how their approach to LT should be adapted to meet individual needs.

\section{CONCLUSIONS}

Participants with SCI experience bodily changes in response to LT. Three themes associated with the changing body were described in this article: (1) experiencing impaired or absent proprioception, (2) struggling for bodily control, and (3) experiencing emerging bodily sensations. The first two themes represent the bodily disruption caused by SCI and the subsequent struggle to reconnect the body with the self through LT. Newly emerging bodily sensations from LT, the third theme, represented reawakening of the body and were perceived as positive signs of recovery by participants. Data indicate that emerging bodily sensations resulted in participant feelings of hope and motivation for further recovery. An understanding of the perspectives of participants undergoing LT can only enhance the provision of participant-centered therapy.

\section{ACKNOWLEDGMENTS}

Dr. Hannold gratefully acknowledges the VA Office of Academic Affairs, the Pre- and Postdoctoral Associated Health Rehabilitation Research Fellowship programs, the VA Rehabilitation Disability Supplement Award program, and the VA Health Services Research and Development/Rehabilitation Research and Development Center of Excellence, Rehabilitation Outcomes Research Center (RORC) for funding this research. This study was conducted in association with Dr. Behrman's locomotor 
training study supported in part by the National Center for Medical Rehabilitation Research (NCMRR)/National Institute of Child Health and Human Development (NICHD), and the VA Brain Rehabilitation Research Center of Excellence (BRRC). We also wish to thank our study participants for their time and commitment to this project. It has been a privilege to share their words.

This material was based on work supported by a VA Pre-Doctoral Associated Health Rehabilitation Research Fellowship (grant TPR 71-002 to Dr. Hannold) and partially supported by the RORC (grant ROC 01-124), the NCMRR/NICHD (grant K01HD01348-01 to Dr. Behrman), and the VA BRRC (grant F2182C).

The authors have declared that no competing interests exist.

\section{REFERENCES}

1. Estores IM. The consumer's perspective and the professional literature: What do persons with spinal cord injury want? J Rehabil Res Dev. 2003;40(4 Suppl 1):93-98. [PMID: 15077653]

2. Kilgore KL, Scherer M, Bobblitt R, Dettloff J, Dombrowski DM, Godbold N, Jatich JW, Morris R, Penko JS, Schremp ES, Cash LA. Neuroprosthesis consumers' forum: Consumer priorities for research directions. J Rehabil Res Dev. 2001;38(6):655-60. [PMID: 11767973]

3 . Anderson KD. Targeting recovery: Priorities of the spinal cordinjured population. J Neurotrauma. 2004;21(10):1371-83. [PMID: 15672628]

4. Brown-Triolo DL, Roach MJ, Nelson K, Triolo RJ. Consumer perspectives on mobility: Implications for neuroprosthesis design. J Rehabil Res Dev. 2002;39(6):659-70.

5. Nelson AL. Patients' perspectives of a spinal cord injury unit. SCI Nurs. 1990;7(3):44-63. [PMID: 2402618$]$

6. Schmitt N. Patients' perception of laughter in a rehabilitation hospital. Rehabil Nurs. 1990;15(3):143-46. [PMID: 2343177]

7. Carpenter C. The experience of spinal cord injury: The individual's perspective-Implications for rehabilitation practice. Phys Ther. 1994;74(7):614-28; discussion 628-29. [PMID: 8016194]

8. Hannold E, Young ME. Consumer perspectives on the revised code of professional ethics for rehabilitation counselors. J Appl Rehabil Couns. 2001;32(4):5-9.

9. Potter M, Gordon S, Hamer P. The physiotherapy experience in private practice: The patients' perspective. Aust J Physiother. 2003;49(3):195-202. [PMID: 12952519]

10. Cott CA. Client-centred rehabilitation: Client perspectives. Disabil Rehabil. 2004;26(24):1411-22. [PMID: 15764361]
11. Liu C, Thompson AJ, Playford ED. Patient dissatisfaction: Insights into the rehabilitation process. J Neurol. 2004; 251(9):1094-97. [PMID: 15372252]

12. Wohlin Wottrich A, Stenstrom CH, Engardt M, Tham K, Von Koch L. Characteristics of physiotherapy sessions from the patient's and therapist's perspective. Disabil Rehabil. 2004;26(20):1198-1205. [PMID: 15371020]

13. Mulholland SJ, Packer TL, Laschinger SJ, Lysack JT, Wyss UP, Balaram S. Evaluating a new mobility device: Feedback from women with disabilities in India. Disabil Rehabil. 2000;22(3):111-22. [PMID: 10749033]

14. Agarwal S, Triolo RJ, Kobetic R, Miller M, Bieri C, Kukke S, Rohde L, Davis JA Jr. Long-term user perceptions of an implanted neuroprosthesis for exercise, standing, and transfers after spinal cord injury. J Rehabil Res Dev. 2003; 40(3):241-52. [PMID: 14582528]

15. Monninkhof E, Van der Aa M, Van der Valk P, Van der Palen J, Zielhuis G, Koning K, Pieterse M. A qualitative evaluation of a comprehensive self-management programme for COPD patients: Effectiveness from the patients' perspective. Patient Educ Couns. 2004;55(2): 177-84. [PMID: 15530752]

16. Woodend AK, Nair RC, Tang AS. Definition of life quality from a patient versus health care professional perspective. Int J Rehabil Res. 1997;20(1):71-80. [PMID: 9089016]

17. Callahan MB, LeSage L, Johnstone S. A model for patient participation in quality of life measurement to improve rehabilitation outcomes. Nephrol News Issues. 1999;13(1): 33-37. [PMID: 10335187]

18. Hobart JC, Riazi A, Lamping DL, Fitzpatrick R, Thompson AJ. Improving the evaluation of therapeutic interventions in multiple sclerosis: Development of a patient-based measure of outcome. Health Technol Assess. 2004;8(9):iii,1-48. [PMID: 14982653]

19. Payton OD, Nelson CE, Ozer MN. Patient participation in planning: A manual for therapists. Philadelphia (PA): F. A. Davis; 1990. p. ix-xii.

20. Ozer MN, Payton OD, Nelson CE. Treatment planning for rehabilitation: A patient-centered approach. New York (NY): McGraw-Hill; 2000. p. 41-72.

21. Colombo G, Joerg M, Schreier R, Dietz V. Treadmill training of paraplegic patients using a robotic orthosis. J Rehabil Res Dev. 2000;37(6):693-700. [PMID: 11321005]

22. Jezernik S, Scharer R, Colombo G, Morari M. Adaptive robotic rehabilitation of locomotion: A clinical study in spinally injured individuals. Spinal Cord. 2003;41(12):657-66. [PMID: 14639444]

23. Field-Fote EC. Spinal cord control of movement: Implications for locomotor rehabilitation following spinal cord injury. Phys Ther. 2000;80(5):477-84. [PMID: 10792858$]$

24. Field-Fote EC. Combined use of body weight support, functional electric stimulation, and treadmill training to 
improve walking ability in individuals with chronic incomplete spinal cord injury. Arch Phys Med Rehabil. 2001; 82(6):818-24. [PMID: 11387589]

25. Barbeau H, Ladouceur M, Mirbagheri MM, Kearney RE. The effect of locomotor training combined with functional electrical stimulation in chronic spinal cord injured subjects: Walking and reflex studies. Brain Res Brain Res Rev. 2002;40(1-3):274-91. [PMID: 12589926]

26. Postans NJ, Hasler JP, Granat MH, Maxwell DJ. Functional electric stimulation to augment partial weight-bearing supported treadmill training for patients with acute incomplete spinal cord injury: A pilot study. Arch Phys Med Rehabil. 2004;85(4):604-10. [PMID: 15083437]

27. Daly JJ, Roenigk KL, Butler KM, Gansen EL, Fredrickson E, Marsolais EB, Rogers J, Ruff RL. Response of sagittal plane gait kinematics to weight-supported treadmill training and functional neuromuscular stimulation following stroke. J Rehabil Res Dev. 2004;41(6):807-20. [PMID: 15685469]

28. Daly JJ, Ruff RL. Feasibility of combining multi-channel functional neuromuscular stimulation with weight-supported treadmill training. J Neurol Sci. 2004;225(1-2):105-15. [PMID: 15465093]

29. Behrman AL, Lawless-Dixon AR, Davis SB, Bowden MG, Nair P, Phadke C, Hannold EM, Plummer P, Harkema SJ. Locomotor training progression and outcomes after incomplete spinal cord injury. Phys Ther. 2005;85(12):1356-71. [PMID: 16305274]

30. Edgerton VR, Roy RR, Hodgson JA, Prober RJ, De Guzman $\mathrm{CP}$, De Leon RD. A physiological basis for the development of rehabilitative strategies for spinally injured patients. J Am Paraplegia Soc. 1991;14(4):150-57. [PMID: 1683668]

31. Harkema SJ, Hurley SL, Patel UK, Requejo PS, Dobkin $\mathrm{BH}$, Edgerton VR. Human lumbosacral spinal cord interprets loading during stepping. J Neurophysiol. 1997;77(2): 797-811. [PMID: 9065851]

32. Barbeau H, McCrea DA, O’Donovan MJ, Rossignol S, Grill WM, Lemay MA. Tapping into spinal circuits to restore motor function. Brain Res Brain Res Rev. 1999; 30(1):27-51. [PMID: 10407124]

33. Barbeau H, Danakas M, Arsenault B. The effects of locomotor training in spinal cord injured subjects: A preliminary study. Restor Neurol Neurosci. 1993;5(1):81-84.

34. Gardner MB, Holden MK, Leikauskas JM, Richard RL. Partial body weight support with treadmill locomotion to improve gait after incomplete spinal cord injury: A singlesubject experimental design. Phys Ther. 1998;78(4):361-74. [PMID: 9555919]

35. Behrman AL, Harkema SJ. Locomotor training after human spinal cord injury: A series of case studies. Phys Ther. 2000;80(7):688-700. [PMID: 10869131]

36. Dobkin B, Apple D, Barbeau H, Basso M, Behrman AL, Deforge D, Ditunno J, Dudley G, Elashoff R, Fugate L,
Harkema SJ, Saulino M, Scott M, Spinal Cord Injury Locomotor Trial Group. Weight-supported treadmill vs overground training for walking after acute incomplete SCI. Neurol. 2006;66(4):484-93. [PMID: 16505299]

37. Visintin M, Barbeau H. The effects of body weight support on the locomotor pattern of spastic paretic patients. Can J Neurol Sci. 1989;16(3):315-25. [PMID: 2766124]

38. De Leon RD, Roy RR, Edgerton VR. Is the recovery of stepping following spinal cord injury mediated by modifying existing neural pathways or by generating new pathways? A perspective. Phys Ther. 2001;81(12):1904-11. [PMID: 11736625]

39. Edgerton VR, De Leon RD, Harkema SJ, Hodgson JA, London N, Reinkensmeyer DJ, Roy RR, Talmadge RJ, Tillakaratne NJ, Timoszyk W, Tobin A. Retraining the injured spinal cord. J Physiol. 2001;533(Pt 1):15-22.

[PMID: 11351008]

40. Harkema SJ. Neural plasticity after human spinal cord injury: Application of locomotor training to the rehabilitation of walking. Neuroscientist. 2001;7(5):455-68. [PMID: 11597104]

41. Nymark J, DeForge D, Barbeau H, Badour M, Bercovitch S, Tomas J, Goudreau L, MacDonal J. Body weight support treadmill gait training in the subacute recovery phase of incomplete spinal cord injury. J Neuro Rehabil. 1998; 12(3):119-38.

42. Protas EJ, Holmes SA, Qureshy H, Johnson A, Lee D, Sherwood AM. Supported treadmill ambulation training after spinal cord injury: A pilot study. Arch Phys Med Rehabil. 2001;82(6):825-31. [PMID: 11387590]

43. Effing TW, Van Meeteren NL, Van Asbeck FW, Prevo AJ. Body weight-supported treadmill training in chronic incomplete spinal cord injury: A pilot study evaluating functional health status and quality of life. Spinal Cord. 2006;44(5):287-96. [PMID: 16186857].

44. Hicks AL, Adams MM, Martin Ginis K, Giangregorio L, Latimer A, Phillips SM, McCartney N. Long-term bodyweight-supported treadmill training and subsequent followup in persons with chronic SCI: Effects on functional walking ability and measures of subjective well-being. Spinal Cord. 2005;43(5):291-98. [PMID: 15685260]

45. Glaser BG, Strauss AL. The discovery of grounded theory: Strategies for qualitative research. New York (NY): Aldine de Gruyter; 1967. p. 61.

46. Patton MQ. Qualitative evaluation and research methods. Thousand Oaks (CA): Sage Publications; 1990. p. 131, 187-188.

47. Berman C, Rose L. Examination of a patient's adaptation to quadriplegia. Phys Ther Case Rep. 1998;1(3):148-56.

48. Seymour W. Remaking the body. New York (NY): Routledge; 1998. p. 1-30. 
49. Duggan CH, Dijkers M. Quality of life_-Peaks and valleys: A qualitative analysis of the narratives of persons with spinal cord injuries. Can J Rehabil. 1999;12(3):179-90.

50. Duggan CH, Dijkers M. Quality of life after spinal cord injury: A qualitative study. Rehabil Psychol. 2001;46(1):3-27.

51. Glesne C. Becoming qualitative researchers: An introduction. 2nd ed. Reading (MA): Longman; 1999. p. 135.

52. Miles, MB, Huberman, AM. Qualitative data analysis: An expanded sourcebook. 2nd ed. Thousand Oaks (CA): Sage Publications; 1994. p. 277-80.
53. Becker G. Disrupted lives: How people create meaning in a chaotic world. Berkeley (CA): University of California Press; 1997. p. 37-58.

54. Ellis-Hill CS, Payne S, Ward C. Self-body split: Issues of identity in physical recovery following a stroke. Disabil Rehabil. 2000;22(16):725-33. [PMID: 11117592]

55. Turner BS. Medical power and social knowledge. 2nd ed. London (England): Sage Publications; 1995. p. 18-19,84-85.

Submitted for publication July 8, 2005. Accepted in revised form August 22, 2006. 